\title{
Textual Note
}

Most of the texts of the poems in this book are taken from editions of his work which Burns saw through the press and with which he was closely associated. This allows readers to experience the texts that Burns's early readers read, and which made the poet's name. Many of our texts are taken from the I 786 Kilmarnock edition of Burns's Poems, Chiefly in the Scottish Dialect or from the expanded ${ }_{17} 87$ Edinburgh edition of that collection. A number of songs are taken from the Scots Musical Museum whose contents were substantially shaped by Burns.

The most obvious difference between the poems as they appear here and the form they took for Burns's readers is that our texts have line-by-line glossing of Scots words. Burns recognised that some glossing was desirable, and from the very first Kilmarnock printing he provided a glossary of Scots words at the end of his book. Some nineteenth-century editions began the practice of having line-by-line glosses beside the poems themselves, since this makes the reading experience more immediate, avoiding any need to turn to the back of the book in mid-poem. Though it is labour-intensive from an editorial point of view, we believe this way of presenting the poems is the one that is most helpful for a modern international audience. Poems have been glossed individually, so that it is not assumed the reader should remember the meaning of a Scots word simply because it has already been glossed fifty pages earlier. Readers can dip into the book anywhere, and be confident that they will find sufficient line-byline glossing.

In the interests of readability, the eighteenth-century 'long s' (which looks very like an ' $\mathrm{f}$ ' to modern readers) has been modernized to an ordinary ' $\mathrm{s}$ '; we have expanded some words left blank (sometimes for political or religious reasons); some inconsistencies in indentation and capitalization have been silently corrected, and numbering of stanzas has been omitted; we have numbered Burns's own footnotes rather than using asterisks; and we have modernized the use of quotation marks. Otherwise the punctuation and spelling of the original texts have generally been maintained since, though it does not always make for absolute consistency, and in some cases Burns's usages are unconventional by present standards, this lets modern readers 
relish a flavour of the pauses, hesitations, and emphases which Burns's early readers experienced. Where a poem was not published in editions of his work which Burns supervised or in the Scots Musical Museum, we have printed a version from a Burns manuscript or from a reliable printed source. This is not a variorum edition, so we have listed alternative manuscript or printed readings only in a very small number of especially interesting instances; however, in the case of the poetry and the prose we have tried to make it clear in our notes which text we are following and where any substantial editorial modification has been made. A separate and more detailed note about the rediscovered poems and fragments which are published in this book appears later. Bearing in mind that it does not list most textual variants, we hope this edition provides texts that are clear, well glossed, reliable, and allow readers to get a good sense of the vivacity of Burns's work. 